\title{
Geometrical Transformations in the Mathematics Textbooks in Kosovo and Catalonia
}

\author{
Xhevdet Thaqi ${ }^{1, *}$, Joaquim Gimenez ${ }^{2}$ \\ ${ }^{1}$ Faculty of Education, University of Gjilan "Kadri Zeka", Kosovo \\ ${ }^{2}$ Faculty of Teacher Training, University of Barcelona, Spain
}

Copyright $\mathrm{O} 2016$ by authors, all rights reserved. Authors agree that this article remains permanently open access under the terms of the Creative Commons Attribution License 4.0 International License

\begin{abstract}
The rationale behind this study concerns the issues school administrators and teachers/prospective teachers face over the progress of these students in mathematics classrooms in two different countries (Spain/Catalonia and Kosovo). This study aimed to present a method of examining primary school mathematics textbooks with the purpose of evaluating students' expected past learning and comparing students' expected geometrical transformations learning across the different curricula. The analytical procedure of the examination of text content as presented in this study is itself a diagnostic technique for assessment of the students' past learning, which addressed the main objective of the study. As a main result, we found that the organization of content is based upon a disconnected way of presentation about transformations, and a few attentions paid to variability issues.
\end{abstract}

Keywords Geometry, Transformation, Mathematics Education, Mathematics Textbooks

\section{Introduction}

We know that it's loose treatment of geometric transformations in primary education and teacher training in many European countries (Svoboda 1999). Faced with the challenges of globalization of education systems and teacher training in mathematics in Europe, we need to know even more recent origins of the students' previous training. Recently there have been developed some comparative studies to show the differences between countries from East and West Europe with different geometric traditions. From a semiotic and anthropological approach, we consider that the textbooks analysis is a tool that realizes the institutional situation between countries. An analysis of textbooks can make important contributions to an understanding of curriculum in a particular country (Kunimune, and et altr. 2009). It would serve to provide a window into the educational system, which might lead to an indication of student's post learning (or intended learning). It is a more accurate diagnostic measure to access the student's probable mathematical skill from the "old" curriculum, and it also provides more insight into the "new" curriculum which may assist in a smoother transition from a curriculum to another curriculum. The quotation by Robitaille (1995) below further stressed the importance of textbook analysis from the mathematics education perspective: "Mathematics textbooks exert a considerable influence on the teaching and learning of mathematics, so understanding of how textbooks vary in their content and approach across countries is an important area of investigation. An analysis of textbooks makes an important contribution to understanding curricula in particular country..." (p.5\&6 $\left.6^{1}\right)$.

In this presentation we intend to examine Primary mathematics curricula in the two countries (Catalonia and Kosovo) and to formulate a comparison of the curricula across nations based on the textbooks geometrical transformation content. The significance of this study is two-fold: At one level, the study provides information about cognitive requirements of geometrical transformations content in elementary textbooks and this information can be used to improve mathematics curriculum and teaching in other countries. At another level, it explores new ways of gaining information from these comparative assessments of mathematics achievement and, possibly, limitations of detailed inference from such testing. Textbook is being used in mathematics classrooms very frequently all over the world (Johansson, 2005). However, the importance of textbook was not realized as much as today. To emphasize that textbooks both reflect national curriculum and influence the teaching practices critically, it has become natural to put a level as "potentially implemented curriculum" between intended curriculum and implemented curriculum (Johansson, 2005). When we consider curricula of countries all around the world we also see that geometrical transformations are very important in school mathematics

${ }^{1}$ Robitaille, 1995 , 
curricula (NCTM 2000).

Our hypothesis is that the notion of geometric transformation is untreated in previous training of the prospective primary teachers, because it appears barely on their primary education as conceptual/relational construction. In particular we plan to observe in Primary school textbooks, what kind of transformations are, and how are they structured? And what is the image of geometrical transformations concept that emerges?. We accept the fact that the visual is of significant importance in the first level of geometrical cognition (Jagoda \& Swoboda, 2011), and according to this theory all perceived regularities are classified as visual structures. The things that inspire children, propel them to action and which undergo control and are reflected upon are: rhythm, order and regularity.

\section{Methodology}

For most teachers of mathematics, the textbook is their primary guide for curriculum implementation. Current prospective primary teachers were formed in the plans of the $90 \mathrm{~s}$ in the case of Catalonia (Spain) and with new programs of 2002 in Kosovo. Therefore we decided to analyse textbooks associated with that period. The criteria for the selections of textbooks were based on the selected textbooks being written in a language comprehensible by us, and that the textbooks were used in countries with a relatively high number of schools institutions. It is anticipated that such an investigation will be of value to those responsible for the correct level of placement of these students. Two sets of textbooks from these countries, Catalonia and Kosovo, were selected for this study. The textbook geometrical transformations content of each country was analysed in terms of strand weighting and content details. The findings facilitated a comparison of the learning paths offered by the various textbooks, fleshed out the differences and similarities of the various curricula and made available detailed comparisons of the textbooks' geometrical transformations content in terms of topics covered. This will decide to choose a text that for some time has had only a Catalan edition, the "Text - la Galeria". It is different in Kosovo. The Ministry of Education of Kosovo (MASHT) decide editor of the textbooks to be used by public schools. In recent years, the editor of the textbook "Dukagjini" were chosen for the subject of mathematics in primary schools, and for this reason we consider these books as reference for the Kosovar context.

The results were analysed and compared among the textbooks of two countries in terms of cognitive domains that these content required. The results were interpreted in the context of the textbooks and relevant curriculum. This interpretation is descriptive in nature and serves as a means to identifying the nature of similarities and differences across the textbooks from Spain/Catalonia and Kosovo in terms of the geometrical transformations concept image (Thaqi, 2009).

According to the Catalan official curriculum, the number of math activities is not determined and it is the teacher who is responsible for planning and developing activities and classes as other conditions and circumstances for each subject. So there is no a priori determined number of classes devoted to math to do in school. Within mathematics classes are planed developing of geometry classes with few activities devoted to geometric transformations.

\section{Geometric Transformations in Curricula and Textbooks}

First we present some benchmarks of the curriculum, compared with those who had at that time in the NCTM standards that began to influence Europe, but not yet actively.

Teaching some geometric transformations has been present in all curricula of primary education, though in different ways. It is based primarily on the study of isometric transformations (symmetries, rotation and translation). Intuitively arises only something on similarity and congruence and projective transformation, but only as construction of plane representation of an object from three-dimensional representation of the object (NCTM) and understand that a" figure is different depending of the point of view that we look "(Catalunya). Little is said about the variation and types of transformations, as well about transformation as process or change and even less about communication and reasoning with transformations and cultural and historical elements in transformations (Svoboda, 2007; Thaqi 2009). Referred only to the "use of geometric ideas to describe situations and to communicate information "(Curriculum Catalunya) but generally as changes of position and not speaking specifically of geometric transformations as functional relationships. Structurally speaking, the processes are applicable verbs like, identifying, recognizing, and building relationships. There are very few connecting verbs and reasoning. Few actions are indicated in the taxonomy of establishing hierarchies and when talking about construction, these actions are related to geometric property of congruence. A transformation is indicated only as change in their intuitive manipulative aspect. Mistakenly used the term generator to find the source element of given transformation and end point, and there is talk of finding the result of a transformation in construction way by different artefacts.

About communication and reasoning, it insists on recognizing that different points of views are associated with different transformations, and it comes in the search for explanations of regularities. No one knows exactly what value are phrases like "Recognize turns and complex symmetries." 
Table 1. Comparative analysis of the curricula about geometric transformations

\begin{tabular}{|c|c|c|}
\hline $\begin{array}{c}\text { Geometric } \\
\text { transformations }\end{array}$ & Catalonia & Kosovo \\
\hline $\begin{array}{l}\text { About the object } \\
\text { transformation, } \\
\text { terminology and types of } \\
\text { transformations (in the } \\
\text { plane) }\end{array}$ & $\begin{array}{c}\text { Symmetry, turns, shadows } \\
\text { Identify figures with symmetry axis, } \\
\text { Understand that figure looks different according to the } \\
\text { viewpoints that look. } \\
\text { Identify the transformation that relates two given figures. }\end{array}$ & $\begin{array}{l}\text { Symmetry, rotation, translation } \\
\text { Differentiate symmetrical figures from unsymmetrical } \\
\text { Identifying relation between two isometric figures } \\
\text { Recognize, name and define different changes of } \\
\text { positions of figures. }\end{array}$ \\
\hline $\begin{array}{l}\text { About the relations and } \\
\text { hierarchies in the notion of } \\
\text { transformation }\end{array}$ & $\begin{array}{l}\text { Composition and Decomposition of figures } \\
\text { Recognize rotations and complex symmetries. } \\
\text { Identify the transformation that relates two given figures. }\end{array}$ & $\begin{array}{l}\text { Identifying relation between two symmetrical and } \\
\text { isometric figures. } \\
\text { Construct congruent with the figure given in relation of } \\
\text { symmetry, rotation and translation. }\end{array}$ \\
\hline $\begin{array}{c}\text { About transformation as a } \\
\text { process or change }\end{array}$ & $\begin{array}{c}\text { Transformations of geometric figures in a manipulative } \\
\text { Recognize what the object that generated a particular } \\
\text { shade }\end{array}$ & $\begin{array}{l}\text { Recognize, describe, classify, name and define the } \\
\text { changes positions of different figure } \\
\text { Construction of symmetric line and bisector } \\
\text { Construct the congruent figure of given figure. }\end{array}$ \\
\hline $\begin{array}{l}\text { About communication and } \\
\text { reasoning by } \\
\text { transformations } \\
\end{array}$ & $\begin{array}{l}\text { Understand that the figure looks different according to } \\
\text { the viewpoints that look. } \\
\text { Recognize complex symmetries and turn. }\end{array}$ & $\begin{array}{l}\text { Regularities of figures from symmetries } \\
\text { Describe, name and define changes of shape positions. }\end{array}$ \\
\hline $\begin{array}{l}\text { About cultural and } \\
\text { historical elements in } \\
\text { transformations }\end{array}$ & Identifying geometric figures using models. & $\begin{array}{c}\text { Differentiating and symmetrical objects from } \\
\text { unsymmetrical. }\end{array}$ \\
\hline
\end{tabular}

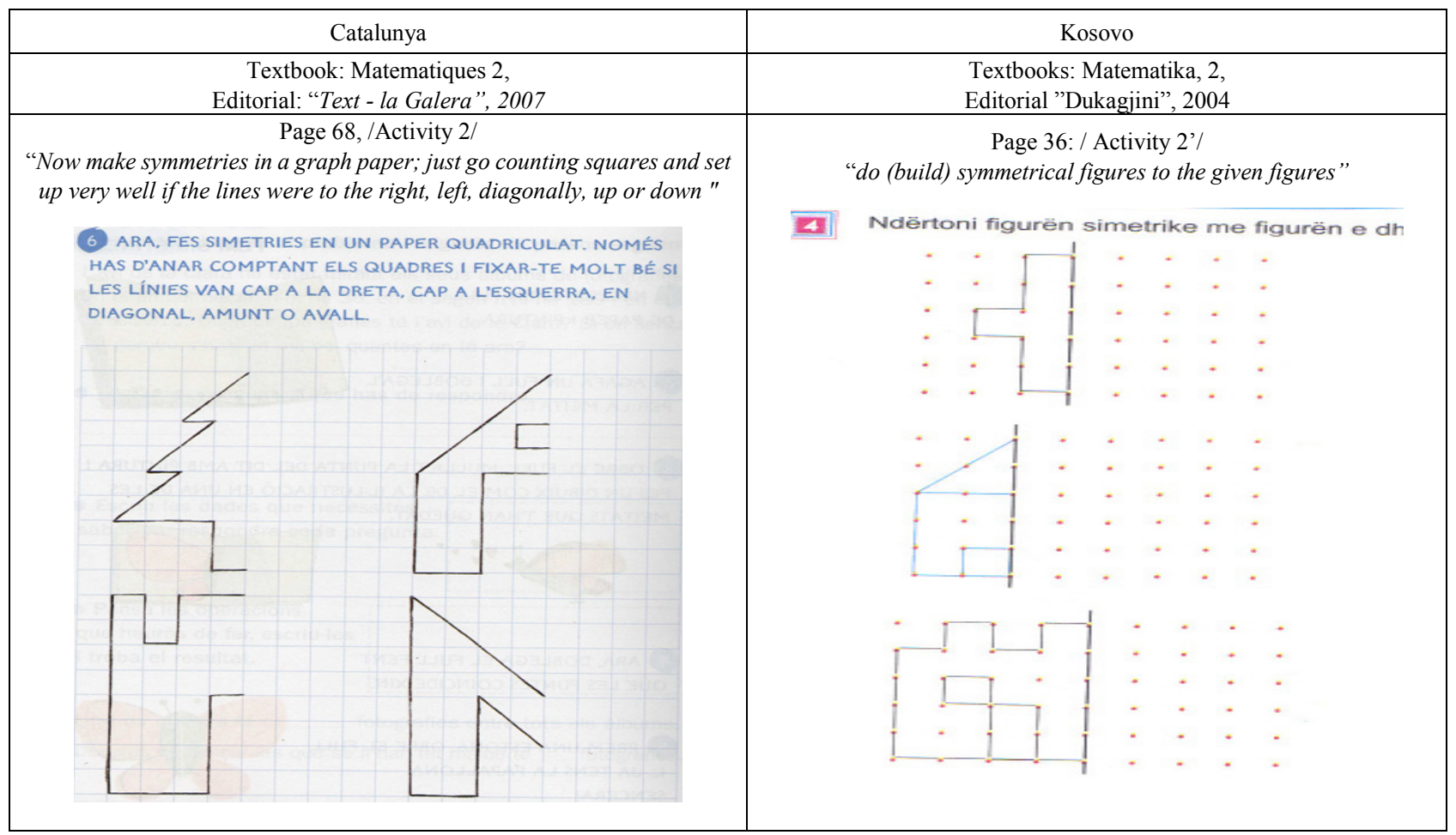

Figure 1. Comparative examples of $2^{\text {nd }}$ grade textbooks of Primary School

\section{Results about Textbooks in Catalonia and Kosovo}

By looking at the analysed textbooks, we can see that in the first cycle (1st and 2 nd grade) symmetry is identified as an important element, though never referred to it as $a$ transformation. Kosovo textbooks only refer to "build the symmetrical". As instructional standards, handling is privileged as the folded paper in Catalan curriculum, emphasizing it as a process. In Kosovar textbooks, seems to distinguish between buildings and transformation. In
Kosovar textbooks properties are analysed according to the Soviet tradition, and change processes are recognized in Catalonia. No conceptual hierarchies are established in the sense of showing that there are "other changes" to different symmetry, nor made explicit the "no symmetry". As shown in Figure 1, both referred to as graph paper simplest form of execution. In both countries are privileged contexts of action over observation of the real-social.

In the textbooks for the Second Cycle of Primary school of two countries, finding axes of symmetry is the most obvious common element. Only in Kosovo textbook the symmetry is 
referred to transformation. In effect, it says "Draw the line of symmetry that transforms one figure to another". In Catalonia textbooks is considered the no isometric transformation - perspective. While both countries are talking for turning in Kosovo textbooks this is always more clearly explicit. The tasks are often more self-explanatory in Catalonia. While in Catalonia are accentuated visualisation processes in Kosovo is accentuated using mathematical terms. Noteworthy is the use of real contexts in the Catalan textbooks, and use of activities without everyday contexts in Kosovo textbooks (Figure 2).

As for the third cycle of primary education, in Catalonian textbooks are accentuated identification processes, and recognition, while in Kosovar textbooks are demanding more identification of properties and conceptualizations. For example, as seen in Figure 3, specifies display perpendicular and equidistant from the axis of symmetry, and the line symmetry of the respective segments formed by points of symmetry. It calls for the description and justification of the visual characteristics of symmetries, identifying, explaining and argue the invariances with symbols respective to symmetry. Interpreting is requested performing symmetric transformation through informal and formal methods, the use and application of symmetries by coordinates (Marchini \& Vighi, 2009). It is requested also observation of equivalence and invariance, identification of symmetry as displacement or application of the elements of the figure (object). Realisation of symmetric transformation of figures performed using displacement or application of the elements of figures.

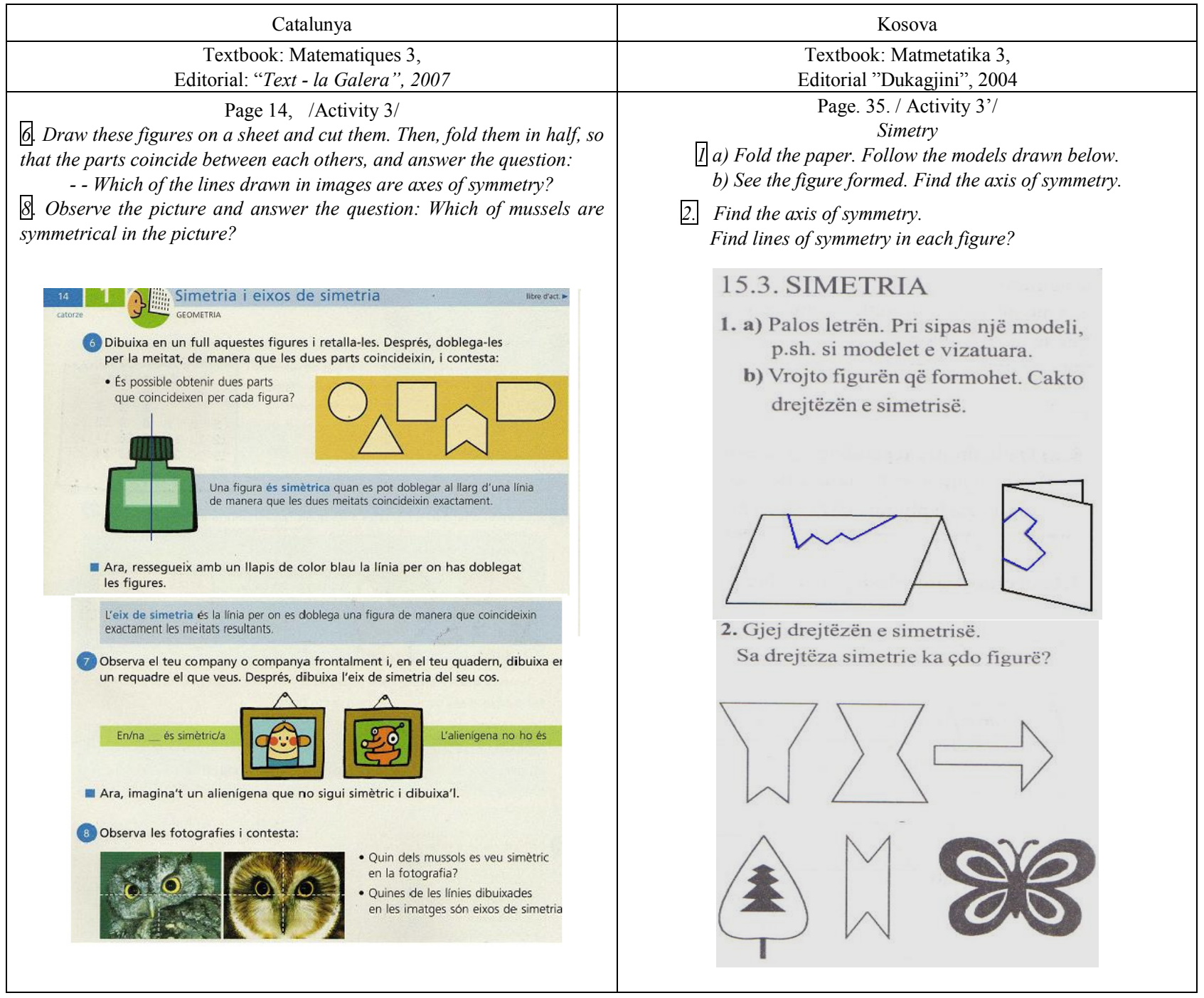

Figure 2. Comparative examples of $3^{\text {rd }}$ grade textbooks of Primary School 


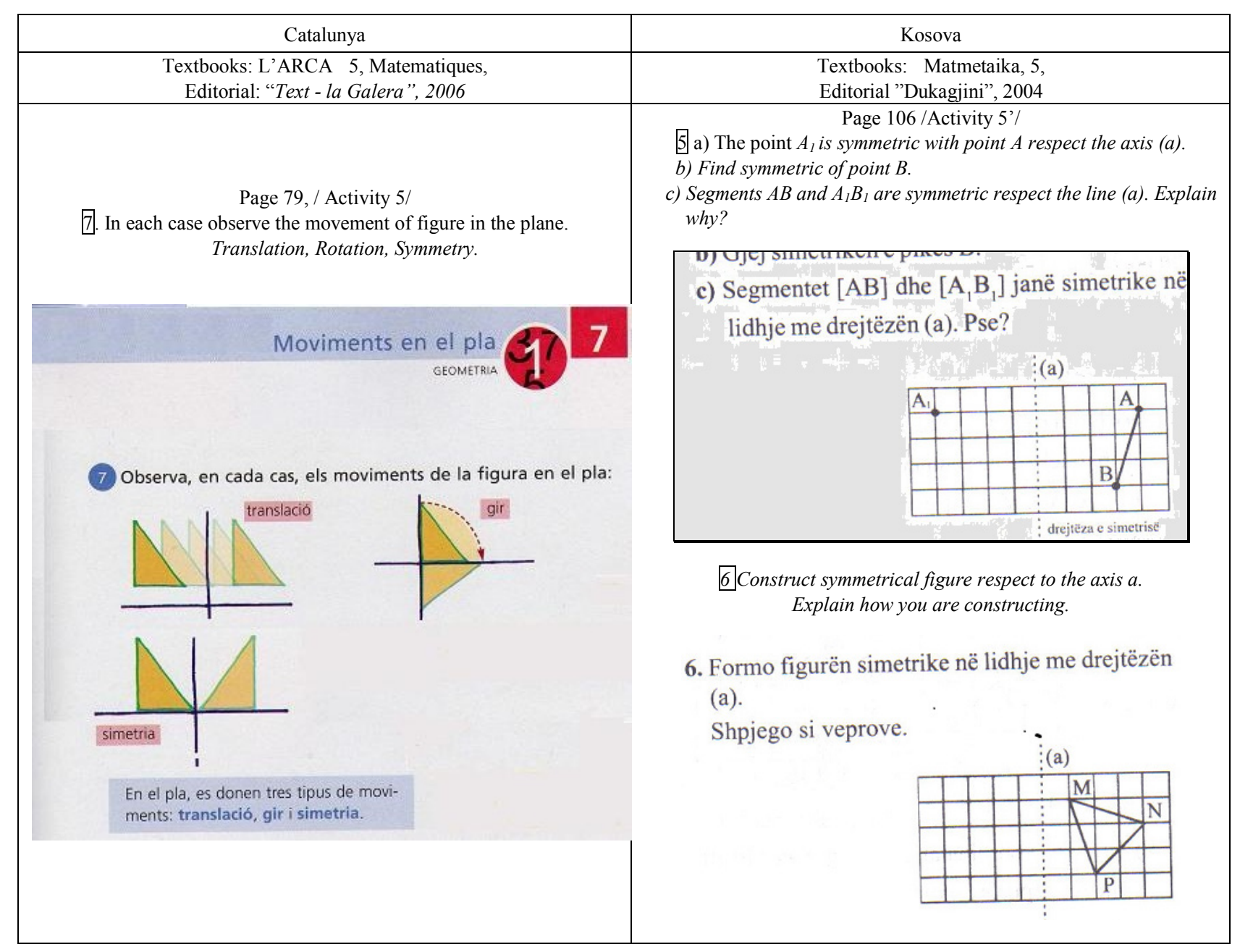

Figure 3. Comparative examples of $5^{\text {th }}$ cicle textbooks of Primary School

\section{Conclusions}

As a consequence of the observed, it is recognized that the transformations of symmetry and rotation remain more alluded in both countries. The translation appears in the Catalan textbook. In Kosovar textbook are identified and used propositions properties associated with the use of coordinates by means of square paper. Indeed, Kosovo activities try to conclude that the line formed by the corresponding symmetrical points form a right angle with axis of symmetry (theorem: the straight line connecting corresponding symmetric points intersects the axis of symmetry by right angle) or tries to show that the axis of symmetry intersects the line segment joining two corresponding points exactly at its midpoint. There is not constructed the idea of geometric transformation from a general viewpoint and shape properties are worked in disconnected way.

The textbooks of any of the two countries do not reflect the curriculum objectives and teachers do not cover these absences. Consider two examples. In Catalonia curriculum is required that pupils in primary "... recognize turns, and make shadows, symmetries and turns ... " and " recognize objects that have generated a particular shade "or " identify the transformation that relates two given figures ... "etc., but there is no activity that would develop it. In Kosovar case said that elementary students should be taught about "building the figure consistent with the figure given in relation of symmetry, rotation and translation," and "building symmetric line, bisector, and regularities of figures in function of symmetries ...". But not develop processes to "recognize, describe, classify, name and define different change positions of figures ...", quoted in the curriculum. There are situations or thoughts on situations where properties have or not, to identify general rules. Is treated just the naive idea that there are almost symmetrical shapes, but seems anecdotal.

Besides the above, taking into account the adequacy assumed in textbooks which pose math formal proposals for primary education in Kosovo and Catalonia, we can say this: The activities posed math textbooks for primary education do not give the possibility to students understanding and building a clear concept of geometric transformation. There is necessary a good prepared professional knowledge teacher 
of primary school. The content presented in textbooks may be useful in the correct and complete construction of the concept of geometric transformation only when the teacher is well prepared to develop activities and to teach them.

\section{REFERENCES}

[1] Jagoda, E., \&Swoboda, E. (2011), Static and dynamic approach to forming: the concept of rotation, Proceedings of CERME7, (pp, 558, 567) University of Rseszow.

[2] Johansson, M. (2005). Mathematics textbooks - The link between the intended and the implemented curriculum. Science. Presented at the The Mathematics Education into the 21 st Century Project, Johor Bahru, Malaysia.

[3] Kunimune, S., Fujita, T.,\& Jones, K. (2009) Strengthening students' understanding of 'prof' in geometry in lower secondary school, Proceedings of CERME6, Lyon. Retrieved from: http://ife.ens-lyon.fr/editions/editions-electroniques/ce rme6/working-group-5

[4] Marchini, C. \&Vighi, P. (2009). Can we develop geometrical understanding by focusing on isometries? A teaching experiment by the means of geometrical artefacts. Proceedings of SEMT '09, (pp. 169-176).

[5] National Council of Teachers of Mathematics. (2000). Principles and Standards for School Mathematics. Reston, VA: NCTM.

[6] Robitaille, D. F., Schmidt, W. H., Raizen, S. A., McKnight, C. C., Britton, E. D., \& Nicol, C. (1993). Curriculum frameworks for mathematics and science (Vol. 1). Vancouver: Pacific Educational Press.

[7] Swoboda, E. (2007). Intuition of geometrical relations in plane in works of 4-7 year old children, Proceedings SEMT '07. International Symposium Elementary Maths Teaching. (pp. 249-257)

[8] Thaqi, Xh. (2009). Aprender a enseñar transformaciones geométricas en Primaria desde una perspectiva cultural. (doctoral dissertation, Barcelona University. Spain). Retrieved from: http://www.tesisenxarxa.net/TDX-0521109104606/ 